\title{
A low-cost sexual ornament reliably signals male condition in the fiddler
}

\section{crab Uca beebei}

Masatoshi Matsumasa ${ }^{a}{ }^{*}$, Minoru Murai ${ }^{b}$, John H. Christy

${ }^{\mathrm{a}}$ Center for Liberal Arts and Sciences, Iwate Medical University, Iwate, Japan

${ }^{\mathrm{b}}$ Tropical Biosphere Research Center, University of the Ryukyus, Okinawa, Japan

${ }^{\mathrm{c}}$ Smithsonian Tropical Research Institute, Balboa, Republic of Panama

*Corresponding author: M. Matsumasa, Department of Biology, Center for Liberal Arts and

Sciences, Iwate Medical University, Yahaba-cho 028-3694, Japan.

Tel: +81-19-651-5111 ext. 5045, 5046 (lab.); Fax: +81-19-698-1839

E-mail address: mmasa@iwate-med.ac.jp

*Correspondence: M. Matsumasa, Department of Biology, Center for Liberal Arts and

Sciences, Iwate Medical University, Yahaba-cho 028-3694, Japan

E-mail address: mmasa@iwate-med.ac.jp 
Word count: 38,007 (including spaces) 
Empirical studies of the reliability of sexual signals are needed to test the prediction that females should prefer males in good condition. We examined whether an attractive sexual signal used by male fiddler crabs, Uca beebei, reliably indicates male condition by measuring male blood-glucose and -lactate levels in the field. The signal is a mud structure, a "pillar," that attracts females for mating. Blood-lactate levels (a measure of energy expenditure) of pillar-builders (P-males) immediately after they built their pillars did not differ from those of non-builders (NP-males), suggesting that the cost of building a pillar is small. However P-male lactate levels were significantly higher than those of NP-males late in the activity cycle after P-males had invested more in vigorous courtship using claw "waving." While P-males maintained their glucose levels (a measure of energy availability as the major fuel for ATP production) around $30 \mathrm{mg} / \mathrm{dl}$ during throughout their daily activity period, NP-males showed significantly lower levels at the middle of the period. These results confirm that pillars reliably signal a male's condition as measured by his ability to maintain a blood glucose level necessary for costly courtship, even thought the construction of a pillar has minimal energetic cost.

Keywords: blood-glucose; blood-lactate; costs; courtship; fiddler crab; reliability; sexual 
signals; Uca beebei 
If male sexual traits are costly, their use or level of expression will vary with male condition (Andersson 1986, 1994) and reliably indicate male quality (Bradbury \& Vehrencamp 1998). However, recent theoretical studies have shown that the cost of cheating, not the cost of signal production or use can maintain signal reliability and that reliable signals can have low costs (Lachmann et al. 2001; Számadó 2011a,b). Nevertheless, an increasing number of studies have demonstrated that male condition affects sexual trait expression. Condition-dependence of sexual signals has been demonstrated experimentally by manipulating the amount or quality of food available to males. For example, addition of carotenoids to the diet increased red or orange coloration in guppies (Kodric-Brown 1989; Grether 2000) and in house finches (Brush \& Power 1976; Hill 1992; Hill \& Montogomerie 1994). Addition of food also has been shown to increase the size of ornaments (Emlen 1994, dung beetles; Hunt \& Simmons 1997, horned beetles; David et al. 2000, stalk-eyes flies). Similar results have been reported in the three-spined stickleback (Millinsky \& Bakker 1990) and flycatchers (Gustaffson et al. 1995). The manipulation of food ration also has been shown to affect male courtship rate (Mappes et al. 1996, Kotiaho 2000 in wolf spiders; Kotiaho 2002 in dung beetles; Wagner \& Hoback 1999, Holtzer et al. 2003, Hunt et al. 2004 in field crickets; Kim et al. 2010 in fiddler crabs). One possible explanation for the condition 
dependence of male sexual signals is that the efficacy cost of signaling links signaling level with male condition regardless of whether male condition and mate quality are correlated (Ryan \& Cummings 2005). In this case one would not expect attractive but low cost signals to be condition-dependent.

Blood lactate concentration is a useful indicator of the intensity of behavioral activities in a variety of animals because the level varies between individuals due to their exercise and anaerobic production of ATP (Houlihan et al. 1984; Pough \& Andrews 1985; van Aardt 1988; Hill et al. 1991; Sneddon et al. 1999; Matsumasa \& Murai 2005). In decapod crustaceans the major substrate of glycolysis is glucose and the haemolymph functions as a transient storage reservoir for glucose removed from cells or tissues (Full \& Herreid 1984; Herreid \& Full 1988). Hence the concentration of glucose in the blood is likely to be controlled by reactions to external stimuli and by the physiological condition (i.e. 'quality') of an individual animal. Matsumasa \& Murai (2005) examined the temporal change in blood glucose concentration for males of the fiddler crab Uca perplexa and found that the variation was widest early in their daily activity period when crabs emerge from their burrows and are active on the surface during low tide. However, glucose levels did not change significantly during the activity period. The concentrations of both blood lactate and glucose in hermit crabs that attacked 
others by rapping on their shells increased with the amount of shell rapping individuals

performed (Briffa \& Elwood 2001).

The condition of an animal reflects its internal state as determined by the whole resources available to it for allocation to different traits and displays (Kotiaho 2002). Candolin (1999) measured lipid content as a measure of internal, physical condition. Food-deprived males of the three-spined stickleback had lower lipid levels but larger red areas compared to fed males indicating that condition-dependent expression can vary between sexual traits. We investigated the relationships between the intensity of courtship and internal condition using blood glucose and lactate levels of males of the fiddler crab Uca beebei in their natural habitat. As in all other fiddler crabs, male $U$. beebei have a single enlarged claw that they wave rhythmically when courting and that they use to fight other males (Crane 1975). Uca beebei live in individual burrows in mixed-sex colonies usually on open, unvegetated mud flats in the mid intertidal zone. The crabs are active on the surface (e.g. feeding, courting and fighting) for about $4 \mathrm{hr}$ daily when their habitat is exposed to the air during the day by the tide. Like other fiddler crabs, U. beebei exhibits a biweekly reproductive cycle with peaks of courtship and mating around the spring tides. (Christy 1988a,b; Backwell et al. 1995). Each day some males construct mud pillars at the entrance of their burrows and all males may do so 
at some time. Males that court from burrows with pillars (P-males) are more likely to attract females, which move between burrows and are exposed to avian predators as they seek a mate, than are males that court from burrows lacking a pillar (NP-males) (Christy 1988b). A series of field experiments showed that pillars contribute substantially to the attractiveness of males that build them and that pillars are attractive because they elicit an orientation response that is selected by predation (Christy 2007; Kim et al. 2009).

P-male $U$. beebei also invest more in claw waving than do NP-males (Christy 1988b); P-males waved their claw (pure waving or waving and feeding simultaneously with their small claw) about $60-75 \%$ of the time, while NP-males waved at most about $15-20 \%$ of the time during peaks in the biweekly courtship period. Similar behavioral differences were seen between male Uca terpsichores that did and did not build wide "hoods" of sand (Christy et al. 2002). Given these differences in time allocated to vigorous courtship we predicted that P-males are in better condition than are NP-males and should have higher concentrations of blood glucose than have NP-males. Previous studies (Mappes et al. 1996; Kotiaho 2000, 2002; Hunt et al. 2004) suggested that males in good condition will expend more energy for sexual display, than will males in poor condition. We examined energy expenditure by $\mathrm{P}$ - and NP-males by measuring their blood lactate concentrations during the peak courtship period. 
To show that blood lactate levels increase in male crabs during waving and that male crabs

mobilize glucose into haemolymph before they wave actively, we compared the temporal changes in blood-glucose and -lactate concentrations and in social activities between P-males and NP-males during a given low-tide period. We made the comparisons daily because the behaviour of $U c a$ species usually changes daily according to changes in the time of the low tide during the day (e.g. Murai et al. 1987; Christy 1988b; Backwell et al. 1995; Jennions \& Backwell 1998).

Pillar-building takes less than 10 min on average (Backwell et al. 1995) and may require relatively little energy. P-males spend less time feeding than do NP-males (Christy 1988b) and they are better fed (Backwell et al. 1995) which may explain why they can spend more time courting females with energetic claw waving but not why only P-males build pillars. Here we examine whether or not pillar building is indeed an energetically low-cost behaviour used only by males in relatively good condition and we discuss possible reasons why this signal may nevertheless be a reliable indicator of male physiological condition.

\section{METHODS}


Study Site, Period and Species

Measurements and observations were made on an inter-tidal mud flat (Rodman flat) on the west bank of Panama Canal in the Republic of Panama (see Christy 1988a, b; Backwell et al. 1995) when the surface activities of males of Uca beebei are not diminished by rain (Christy 1988a). The mud flat is submerged by all high tides and exposed by all low tides. Mixed-sex colonies of $U$. beebei are seen on mud banks along the creeks. This study was carried out in one high-density colony during periods with higher amplitude (spring) tides when most courtship occurs. The air temperature in Panama is relatively high during the dry season from January to April (mean maximum temperature $>33.3^{\circ} \mathrm{C}$; mean minimum temperature $>18.4^{\circ} \mathrm{C}$ for the 30 -year period from 1971 to 2000 ; World Weather Information Service, World Meteorological Organization: http://www.worldweather.org/index.htm). Air temperature strongly influenced the blood-glucose and -lactate levels of Uca perplexa (Matsumasa \& Murai 2005). Therefore, we conducted the present study 24 February to 16 March 1999 and from 19 to 26 February 2000 during the dry season when the air temperatures $>28^{\circ} \mathrm{C}\left(\right.$ mean $\pm \mathrm{SD}$ in air temperature during the study was $30.4 \pm 1.13^{\circ} \mathrm{C} ; N=$ 115). The observations on social behaviour were carried out from 2 to 18 January, from 17 
February to 17 March 1999 and from 4 to 11 March 2000. P- and NP-males were observed and blood samples from both classes of males were taken on the same days during spring tide periods.

Frequency and Timing of Pillar Building

Changes in behaviour of males during their surface activities, including the timing of pillar building, were reported by Christy (1988a, b). To schedule blood sampling relative to the time when males built pillars we confirmed the timing of pillar-building in two ways. First we counted the surface-active males, waving males and males that had built their pillars in 4 quadrats of $1 \mathrm{~m}^{2}$ on each of three days. Counts were made at 30 min intervals starting $1 \mathrm{~h}$ before the low tide (LT) of the day and ending $2 \mathrm{~h}$ after LT. Second, in another plot of $1 \mathrm{~m}^{2}$ we counted the number of pillars every $30 \mathrm{~min}$ from $2.5 \mathrm{~h}$ before LT to $2.5 \mathrm{~h}$ after LT. We also recorded the time when male crabs first emerged from their burrows during low tides for 136 NP-males and 141 P-males. 
Activities of P-males and NP-males were observed ( $N=14$ for each type) directly or through binoculars for two periods of $1 \mathrm{~h}$ before LT (i.e. during the 'middle' stage of activity defined in the next section) and after LT (i.e. from the end of the 'middle' to just before the 'late' stages of activity, also defined in the next section). The observers sat still more than $2 \mathrm{~m}$ from the male, and recorded its behaviour with respect to 11 categories used by Christy (1988a) (Table 1) every 1 min during each observation period. The counts of the behavioral categories were contrasted between P-males and NP-males by Mann-Whitney $U$-tests using SYSTAT (Wilkinson 1992).

Measurement of Blood-glucose and-lactate Levels

To examine the blood-glucose and -lactate levels of P-males and NP-males, haemolymph samples $(\mathrm{ca} .50 \mu \mathrm{l})$ were collected from adult males $(7.30-11.85$ and $8.00-11.20 \mathrm{~mm}$ of the carapace width (CW) for NP-males and P-males, respectively) during daytime low tides for the following three stages of the activity cycle: (1) 'early' (2-1 h before LT; $N=15),(2)$ 'middle' (1-0 h before LT; $N=15)$, and (3) 'late' (1-2 h after LT; $N=15)$. Haemolymph 
samples (ca. $50 \mu 1$ ) were removed with a syringe from the arthrodial membrane at the base of pereiopods (Matsumasa et al 2001). Blood-glucose and -lactate levels were determined immediately in the field using a blood-lactate test meter (ARKRAT LactatePro; Yokoe \& Nishimara 1999) and a blood-glucose meter (Fuji DryChem 100 typeG) powered by batteries. Most males (70\%) that build a pillar on a given day also build one the next day (Backwell et al. 1995). P-males began to build pillars about $1 \mathrm{~h}$ before LT (Christy 1988b; see also Fig. 1). Hence, in order to sample the blood of P and NP males early in the activity period before pillars were built we needed to select males of the two classes the day before we took the samples. We did this by marking burrows of P-males and NP-males near the burrow entrances using blue and red pins, respectively. Marks were placed at the end of the crabs' surface activities; the following day haemolymph was sampled from males that emerged from the marked burrows. Thus, haemolymph samples for the 'early' stage (2-1 h before LT) were collected from males at burrows marked the previous day as belonging to P-males and NP-males. For both 'middle' stage samples (1-0 h before LT) and "late" stage samples (1-2 h after LT) haemolymph was collected from previously marked P-males with new pillars and previously marked NP-males that did not build pillars. The $\mathrm{CW}$ of crabs from which haemolymph was sampled was measured with digital calipers. These crabs were marked on 
their carapace with red, blue or yellow ink to avoid recapture, and then released to the field.

The small amount of haemolymph removed from a male was not lethal and did not appear to affect its behaviour after a few hours. The ink marks usually fade away in about a week (personal observation). Hence, drawing blood and marking crabs had no obvious negative longer-term effects. No license was required for this study. All differences of measures between P-males and NP-males were examined for each stage in the activity cycle by Mann-Whitney $U$-tests using SYSTAT (Wilkinson 1992). The above sampling design underestimates differences in blood-glucose and -lactate levels between P-males and NP-males for the 'early' stage, because some P-males would not and some NP-males would build pillars on the second day (see Results).

We also recorded the time when all marked P-males and NP-males first emerged from their burrows. We exclude males that had had their blood sampled and the small number of P-males that did not rebuild pillars and NP-males that built pillars. We compared the emergence time between P-males and NP-males by the Kolmogorov-Smirnov two-sample test with two-sided probability. 
Timing of Pillar Building

The proportion of males with pillars among all males active on the surface increased sharply after low tide as did the proportion of males that were waving (Fig. 1a). Most pillars remained erect during a giving activity period so that the density of pillars increased with time (Fig. 1b). More than $80 \%$ of P-males and almost all NP-males were active on the surface before LT (Fig. 1c, d). Thus, male behaviour changed as the activity period progressed and pillar building was conspicuous after LT. P-males became active on the surface significantly later than NP-males (the Kolmogorov-Smirnov two-sample test: $D=0.28, N_{1}=141, N_{2}=136$, $P<0.001)$

Blood Glucose and Lactate: P-males vs. NP-males

The blood glucose concentrations in the 'early' stage of surface activity (2-1 h before LT) of both P-males and NP-males showed narrow ranges, with the range increasing considerably in 'middle' stage of activity (1-0 h before LT). P-males maintained their blood glucose level 
around $30 \mathrm{mg} / \mathrm{dl}$ in all three stages, while NP-males did not (Fig. 2). The blood glucose concentration of NP-males was significantly lower than that of P-males in 'middle' stage $(U=$ 45.00, $\left.N_{1}=N_{2}=15, P=0.005\right)$. The blood lactate concentration showed wide ranges in both P-males and NP-males, and the median was higher in P-males than in NP-males in all three stages (Fig. 2). The blood-lactate level of P-males was significantly higher than that of NP-males in the 'late' activity stage (1-2 h after LT; $\left.U=61.50, N_{l}=N_{2}=15, P=0.034\right)$.

Crab Behaviour: P-males vs. NP-males

The behaviour of the two classes of males relative to the 11 behavioral categories differed significantly during 1-0 h before LT (the 'middle' activity stage) (Fig. 3). NP-males engaged in "Feeding" more than did P-males $\left(U=164.50, N_{1}=N_{2}=14, P=0.002\right)$. P-males (by definition) exhibited more "Pillar building" $\left(U=47.00, N_{1}=N_{2}=14, P=0.008\right)$, "Wave-feeding" $\left(U=37.00, N_{l}=N_{2}=14, P=0.005\right)$, "Waving" $\left(U=314.00, N_{1}=N_{2}=14\right.$, $P=0.002)$, "Threat" $\left(U=45.00, N_{1}=N_{2}=14, P=0.014\right)$ and "Combat" $\left(U=47.50, N_{1}=N_{2}\right.$ $=14, P=0.017$ ) than NP-males. During 0-1 hr. after LT (i.e., from the end of the 'middle' stage to the beginning of 'late' stage of activity), NP-males also exhibited "Feeding" more 
frequently than P-males, which males seldom fed $\left(U=187.50, N_{l}=N_{2}=14, P<0.001\right)$.

P-males exhibited more "Pillar building" $\left(U=47.00, N_{l}=N_{2}=14, P=0.008\right)$, "Waving" ( $U$ $\left.=314.00, N_{l}=N_{2}=14, P=0.002\right)$ and "Threat" $\left(U=45.00, N_{l}=N_{2}=14, P=0.014\right)$ than NP-males. In particular, P-males spent much time "Waving” whereas NP-males waved very little.

\section{DISCUSSION}

It appears to be energetically costly for male fiddler crabs to wave their major claw which may reach $50 \%$ of the male's total body weight (Crane 1975). Male fiddler crabs $U c a$ perplexa that waved and fought with their major claw had higher blood lactate levels than those that fed and only carried their large claw (Matsumasa \& Murai 2005). In Uca beebei, blood-lactate concentration of P-males did not differ from that of NP males $0-1 \mathrm{~h}$ before LT when males had begun to build their pillars (Fig 1b, Fig 3) but was significantly higher 1-2 $\mathrm{h}$ after LT after P-males had been courting vigorously with claw waving. It takes males only about 10 minutes to build a pillar and this behavior evidently is less costly, as measured by blood lactate levels, than is prolonged claw waving. P-males waved much more vigorously 
and evidently paid a higher metabolic cost than did NP-males during the peak courting period

$1 \mathrm{~h}$ after LT. P-males also more often engaged in combat and threat than did NP-males, though these aggressive interactions were much less frequent than was waving. NP-males spent most of their time feeding during the low tide period ( $1 \mathrm{~h}$ before and after LT). P-males fed most $0-1 \mathrm{~h}$ before LT but rarely fed after LT. Nearly $20 \%$ of P-males became active on the surface after LT (Fig. 1d), indicating that they fed little or not at all. The results of this study strongly suggest that P-males are in better condition when they emerge from their burrows than are NP males. While the blood-glucose levels of P- and NP-males were around $30 \mathrm{mg} / \mathrm{dl}$ during the low tide, P-males showed significantly higher values than NP-males before ( $0-1 \mathrm{~h}$ before LT) the peak courting period. .Hence, P-males maintained a higher level of blood glucose as a source of energy for ATP production for energetically costly claw waving than did NP-males.

Males in relatively better condition built pillars yet pillar building does not appear to be energetically costly. Why is production of this low-cost signal condition-dependent? Christy et al. (2002) found that the sand hoods built by male $U$. terpsichores did not increase male-female encounter rates and, in one experiment, even decreased them. Hence hoods do not attract distant females into a male's courtship range. The fiddler crab visual system is 
highly sensitive to motion (Zeil \& Hemmi 2006) and it is likely that vigorous "background" waving (undirected waving; Pope 2005) with an elevated claw (Murai \& Backwell 2006) is what attracts females to males from a distance. We therefore suggest that vigorous claw waving by male $U$. beebei attracts distant females. Once a female approaches a male, the male leads the female toward his burrow and enters it leaving the visual stimulus of the pillar to guide the female's final approach to the burrow entrance (Christy \& Salmon 1984; Christy 1988b). Thus the utility of pillars as visual guideposts to males' burrows may depend on the close approach of a female, which in turn depends on male investment in vigorous courtship: two stimuli have been found to be more effective than one in eliciting responses from receivers (see Candolin 2003). If a male built a pillar but did not court vigorously and attract distant females, the male would receive scant return on its investment in building the pillar however small that investment may be. In addition, once a male builds a pillar, his burrow probably becomes more apparent to males that are wandering and fighting for burrows and to females not seeking mates (Christy 1988b). Christy (1988a) compared rates of aggressive interactions between P-males and neighboring NP-males before and after pillars were built. The rate did not significantly increase after pillars were built. Yet it is uncertain whether or not there is a difference between relative frequencies with which $\mathrm{P}$ and NP males fight with 
wandering males; further studies are needed. Hence, a male with a pillar may incur

considerably greater costs and risk of burrow loss due to the greater frequency with which crabs other than receptive females orient to their burrows. These socially imposed costs of having a pillar (signal possession) due to responses to pillars from unintended receivers may suppress pillar building by males in relatively poor condition, even though energetic cost of building a pillar (signal production) appears to be small. There is considerable evidence that the sand hoods built by male Uca terpsichores and the mud pillars built by male Uca beebei attract females because they elicit a response that is selected by predation and incidentally leads to mate choice (Christy 2007). Most convincing perhaps are two recent experimental field studies showing that the female preference for males with courtship structures increases with females' perceived risk of predation while they search for mates (U. terpsichores, Kim et al 2007; U. beebei, Kim et al. 2009). Hence, females may enjoy a direct benefit of reduced predation risk when they respond to courtship structures by approaching them and their builders. While the direct benefit of orienting to objects on the surface of intertidal mud and sand flats appears sufficient to maintain the orientation response in species of fiddler crabs that do not build courtship structures (Christy 1995), it does not preclude the possibility that females of structure-building species benefit additionally by mating with males that build 
structures. The present study showed that P-males are in better condition than are NP-males corroborating a previous study showing that males given access to supplemental food build more pillars (Backwell et al. 1995; see Kim et al. 2010 for evidence of condition-dependent signaling by male $U$. terpsichores). Male $U$. beebei will stay with their mates for a day or more. They then leave the burrow and their mate after which other crabs may use the burrow, or at least the upper shaft, while the female incubates her eggs in the original terminal chamber (Christy 1987). P-males and NP- males differ in how long they will stay with their mates: P-males usually remain with their mates until they have ovulated but NP-males seldom do (J. Christy \& P. Backwell unpublished). By mating with a P-male in good condition, a female may benefit directly from being defended by her mate until she has completed ovulation undisturbed by other crabs regardless of the heritability of traits affecting male condition. If male traits that promote condition are heritable and condition affects viability then by mating males in good condition, those that build pillars, females also may obtain genetic benefits for her offspring.

Our study confirms that pillar building by courting male $U$. beebei reliably signals the pillar builder's good condition even though the signal is not costly to produce. Indeed, signals that mediate communication that is mutually beneficial to sender and receiver, as appears to 
be the case for pillars, need not be costly. However, effectiveness of pillars may increase with the level of male investment in costly claw waving. Hence the functional interdependence of the two kinds of signals may ensure that the less costly one nevertheless reliably signals male condition. In addition, the socially mediated costs of having a pillar might also contribute to the condition-dependent nature of pillar building. Empirical studies are needed to demonstrate that production or use of a sexual signal depends on the condition of the signaler. Such studies have been motivated primarily to test whether a signal reliably indicates the quality of a male as a mate. However, condition dependence can arise as a result of competition among males to produce the most effective signal regardless of its "meaning" (Ryan \& Cummings 2005) and signal reliability need not be determined by signal cost and or signaler condition (Számadó 2011a). There are many reasons why a signal may be condition dependent. The example we provide in this study shows that condition dependence of a sexual signal can arise even when sexual signaling is inexpensive and mutually beneficial to male and female and when the benefit to females is likely to be direct and immediate rather than deferred due to the heritability of traits affecting condition and viability. 
References

van Aardt, W. J. 1988. L-Lactate metabolism and glucose patterns in the river crab,

Potamonautes warreni (Calman) during anoxia and subsequent recovery. Comparative Biochemistry and Physiology A, 91, 299-304.

Andersson, M. B. 1986. Evolution of condition-dependent sex ornaments and mating preferences: sexual selection based on viability differences. Evolution, 40:804-816.

Andersson, M. B. 1994. Sexual selection. Princeton: Princeton University Press.

Backwell, P. R. Y., Jennions, M. D., Christy, J. H. \& Schober, U. 1995. Pillar building in the fiddler crab Uca beebei: evidence for a condition-dependent ornament. Behavioral Ecology and Sociobiology, 36,185-192.

Bradbury, J. W. \& Vehrencamp, S. L. 1998. Principles of Animal Communication.

Sunderland, Sinauer.

Briffa, M. \& Elwood, R. W. 2001. Decision rules, energy metabolism and vigor of hermit crab fights. Proceedings of the Royal Society of London B, 268,1841-1848.

\section{Brush,}

effect of diet. $A u k, 93,725-739$. 
Candolin, U. 1999. The relationship between signal quality and physical condition: is sexual signaling honest in the three-spined stickleback? Animal Behaviour, 58, 1261-1267.

Candolin, U. 2003. The use of multiple cues in mate choice. Biological Review, 78, 575-595.

Christy, J. H. 1987. Female choice and the breeding behavior of the fiddler crab Uca beebei. Journal of Crustacean Biology, 7, 624-635.

Christy, J. H. 1988a. Pillar function in the fiddler crab Uca beebei (I): effects on male spacing and aggression. Ethology, 78, 53-71.

Christy, J. H. 1988b. Pillar function in the fiddler crab Uca beebei (II): competitive courtship signaling. Ethology, 78, 113-128.

Christy, J. H. 1995. Mimicry, mate choice, and the sensory trap hypothesis. American Naturalist, 146, 171-181.

Christy, J. H. 2007. Predation and the reproductive behavior of fiddler crabs (genus Uca). In: Evolution of Social Behavior of Crustaceans (Ed. by M.Thiel \& J.E.Duffy), pp. 211-231. Oxford: Oxford University Press.

Christy, J. H., Backwell, P. R. Y., Goshima, S. \& Kreuter, T. 2002. Sexual selection for structure building by courting male fiddler crabs: an experimental study of behavioral mechanisms. Behavioral Ecology, 13, 366-374. 
Christy, J. H. \& Salmon, M. 1984. Ecology and evolution of mating systems of fiddler crabs (genus Uca). Biological Review, 59, 483-509.

Crane, J. 1975. Fiddler crabs of the world: Genus Uca. Princeton: Princeton University Press.

David, P., Bjorksten, T., Fowler, K. \& Pomiankowski, A. 2000. Condition-dependent signalling of genetic variation in stalk-eyed flies. Nature, 406,186-188.

Emlen, D. J. 1994. Environmental control of horn length dimorphism in the beetle Onthophagus acuminatus (Coleoptera: Scarabaeidae). Proceedings of the Royal Society of London $B, \mathbf{2 5 6}, 131-136$.

Full, R. J. \& Herreid, C. F. II 1984. Fiddler crab exercise: the energetic cost of running sideways. Journal of Experimental Biology, 109,141-161.

Grether, G. F. 2000. Carotenoid limitation and mate preference evolution: a test of the indicator hypothesis in guppies (Poecilia reticulata). Evolution, 54, 1712-1724.

Gustaffson, L., Qvarnstrom, A. \& Sheldon, B. C. 1995. Trade-offs between life-history traits and secondary sexual character in male collared flycatchers. Nature, 375, 311-313.

Herreid, C. F. II \& Full, R. J. 1988. Energetics and locomotion. In: Biology of the Land Crabs (Ed. by W. W. Burggren \& B. R. McMahon B.R.), pp. 333-377, Cambridge: 
Cambridge University Press.

Hill, A. D., Taylor, A. C. \& Strang, R. H. C. 1991. Physiological and metabolic responses of the shore crab, Carcinus maenus. Journal of Experimental Marine Biology and Ecology, 150, 31-50.

Hill, G. E. 1992. The proximate basis of variation in carotenoid pigmentation in male house finches. Auk, 109, 1-12.

Hill, G. E. \& Montogomerie, R. 1994. Plumage colour signals nutritional condition in the house finch. Proceedings of the Royal Society of London B, 258, 47-52.

Holzer, B., Jacot, A. \& Brinkhof, M. W. G. 2003. Condition-dependent signaling affects male sexual attractiveness in field crickets, Gryllus campestris. Behavioral Ecology, 14, 353-359.

Houlihan, D. F., Mathers, E. \& Haj, A. E. 1984. Walking performance and aerobic and anaerobic metabolism of Carcinus maenas. Journal of Experimental Marine Biology and Ecology, 74, 211-230.

Hunt, J., Brooks, R., Jennions, M. D., Smith, M. J., Bentsen, C. L. \& Bussière, L. F. 2004. High-quality male field crickets invest heavily in sexual display but die young. Nature, 432, 1024-1027. 
Hunt, J. \& Simmons, L.W. 1997. Patterns of fluctuating asymmetry in beetle horns: an experimental examination of the honest signaling hypothesis. Behavioral Ecology and Sociobiology, 41, 109-114.

Jennions, M. D. \& Backwell, P. R. Y. 1998. Variation in courtship rate in the fiddler crab Uca annulipes: is it related to male attractiveness? Behavioral Ecology, 9, 605-611.

Kim, T. W., Christy, J. H. \& Choe, J. 2007. A preference for a sexual signal keeps females safe. PLoS-One, 2 , e422.

Kim, T. W., Christy, J. H., Dennenmoser, S., \& Choe, J. 2009. The strength of a female mate preference increases with predation risk. Proceedings of the Royal Society of London $B, \mathbf{2 7 6}, 775-780$.

Kim, T. W., Christy, J. H., Rissanen, J. R. Ribeiro, P. D. \& Choe, J. 2010. The effect of food addition on the reproductive intensity and timing of both sexes of an intertidal crab. Marine Ecology Progress Series, 401, 183-194.

Kodric-Brown, A. 1989. Dietary carotenoids and male mating success in the guppy: an environmental component to female choice. Behavioral Ecology and Sociobiology, 25, $393-401$.

Kotiaho, J. S. 2000. Testing the assumptions of conditional handicap theory: costs and 
condition dependence of a sexually selected trait. Behavioral Ecology and Sociobiology,

48, 188-194.

Kotiaho, J. S. 2002. Sexual selection and condition dependence of courtship display in three species of horned dung beetles. Behavioral Ecology, 13, 791-799.

Lachmann, M., Számadó, S. \& Bergstrom, C. T. 2001. Cost and conflict in animal signals and human language. Proceedings of the National Academy of Science, 98, 13189-13194.

Mappes, J., Alatalo, R.V., Kotiaho, J. \& Parri, S. 1996. Viability costs of condition -dependent sexual male display in a drumming wolf spider. Proceedings of the Royal Society of London B, 263, 785-789.

Matsumasa, M., Kikuchi, S., Takeda, S., Poovachiranon, S., Yong, H. S. \& Murai, M. 2001. Blood osmoregulation and ultrastructure of the gas windows ('tympana') of intertidal ocypidid crabs: Dotilla vs. Scopimera. Benthos Research, 56, 47-55.

Matsumasa, M. \& Murai, M. 2005. Changes in blood glucose and lactate levels of male fiddler crabs: effects of aggression and claw waving. Animal Behaviour, 69, 569 -577.

Millinsky, M. \& Bakker, T. C. M. 1990. Female sticklebacks use male coloration in mate choice and hence avoid parasitized males. Nature, 344, 330-333.

Murai, M. \& Backwell, P. R. Y. 2006. A conspicuous courtship signal in the fiddler crab 
Uca perplexa: female choice based on display structure. Behavioral Ecology and

Sociobiology, 60, 736-741.

Murai, M., Goshima, S. \& Henmi, Y. 1987. Analysis of the mating system of the fiddler crab, Uca lactea. Animal Behaviour, 35, 1334-1342.

Pope, D. 2005. Waving in a crowd: fiddler crabs signal in networks. In: Animal Communication Networks (Ed. by P. K. McGregor), pp. 252-276. Cambridge: Cambridge University Press.

Pough, F. H. \& Andrews, R. M. 1985. Use of anaerobic metabolism by free-ranging lizard. Physiological Zoology, 58, 205-213.

Ryan, M. J. \& Cummings, M. E. 2005. Animal signals and the overlooked costs of efficacy. Evolution, 59, 1160-1161.

Számadó, S. 2011a. The cost of honesty and the fallacy of the handicap principle. Animal Behaviour, 81, 3-10.

Számadó, S. 2011b. Long-term commitment promotes honest status signalling. Animal Behaviour, 82, 295-302.

Sneddon, L. U., Taylor, A. C. \& Huntingford, F. A. 1999. Metabolic consequences of agonistic behaviour: crab fights in declining oxygen tensions. Animal Behaviour, 57, 
$353-363$.

Wagner, W. E. \& Hoback, W.W. 1999. Nutritional effects on male calling behaviour in the variable field cricket. Animal Behaviour, 57, 89-95.

Wilkinson, L. 1992. SYSTAT, Version 5.2. Evanston, Illinois, SYSTAT, Inc.

Yokoe, Y. \& Nishimura, S. 1999. Basic evaluation of lactate meter using disposable electrochemical sensor. The Cell, 31, 26-28.

Zeil, J. \& Hemmi, J. M. 2006. The visual ecology of fiddler crabs. Journal of Comparative Physiology A, 192, 1-25. 
Table 1

Behavioral categories used by Christy for males of Uca beebei (see Christy 1988a for more details)

Category Description

In burrow $\quad$ Crab in its burrow and can not be seen or motionless and partially visible in its burrow

entrance.

Nothing Crab motionless on the surface in a relaxed posture.

Pose Crab raised on the dactyls of its nearly straight walking legs. Large chela usually

extended laterally with its tip touching the ground, usually remaining in this posture for

several min.

Clean Crab grooms parts of its body with its small chela and rubs its walking legs together.

Dig Crab alternately enters its burrow and returns to the surface carrying material from

inside its burrow and depositing it on the substrate surface.

Pillar building Male scratches and picks up mud substrate from around his burrow and stacks it at his burrow entrance.

Feed

Crab walks slowly, removes bits of substrate from the surface with its small chela and 
places them in its mouth.

Wave-feed Male rhythmically raises and extends its large chela while walking and feeding.

Wave

Same as above but not feeding. Claw movements become more vigorous when female

is near. Male alternately moves toward its burrow and back slightly toward the female.

Threat

Movements of the large claw males direct to other crabs, usually males, that do not

involve interdigitation of males' chelae.

Combat Movements or postures in which males' chelae usually are intertwined. Includes reach,

dig-out, interdigitation, grip, attempted flip and flip. 
Acknowledgments

We thank the Smithsonian Tropical Research Institute for support and the Unidad

Administrativa de Bienes Revertidos of the Ministerio de Economía y Finanzas, the

Servicio Nacional Aeronaval, and the Autoridad del Canal de Panama (ACP), Republic

of Panama, for access to the field site in the intertidal zone near the old Rodman Naval

Base. This study was also supported by a Grant-in-Aid from the Japan Society for the

Promotion of Science (No. 10041175 and 22570027). This research conformed to the

ethical guidelines of Iwate Medical University. 

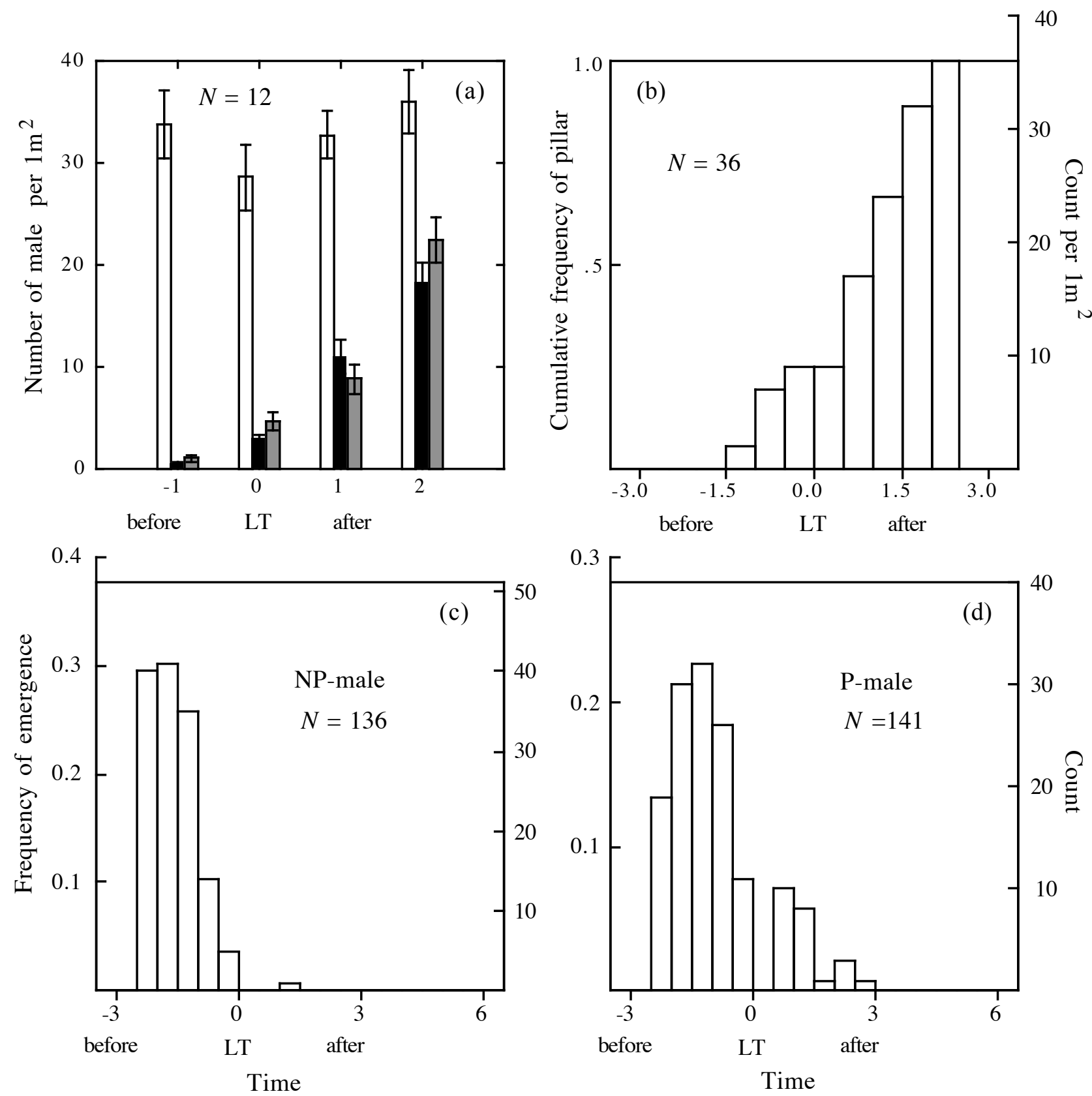
Figure 1. Mean densities ( \pm 1SE) of waving males (shaded bar), pillar males (black bar) and surface-active males (total males; white bar) observed from $1 \mathrm{~h}$ before LT to $2 \mathrm{~h}$ after LT (a). Cumulative number of pillars in a plot observed from $2.5 \mathrm{~h}$ before LT to $2.5 \mathrm{~h}$ after LT (b). Frequencies of non-pillar males and pillar-males that first emerged from their burrows from $3 \mathrm{~h}$ before LT to $6 \mathrm{~h}$ after LT (c, d). 
2-1 h before LT
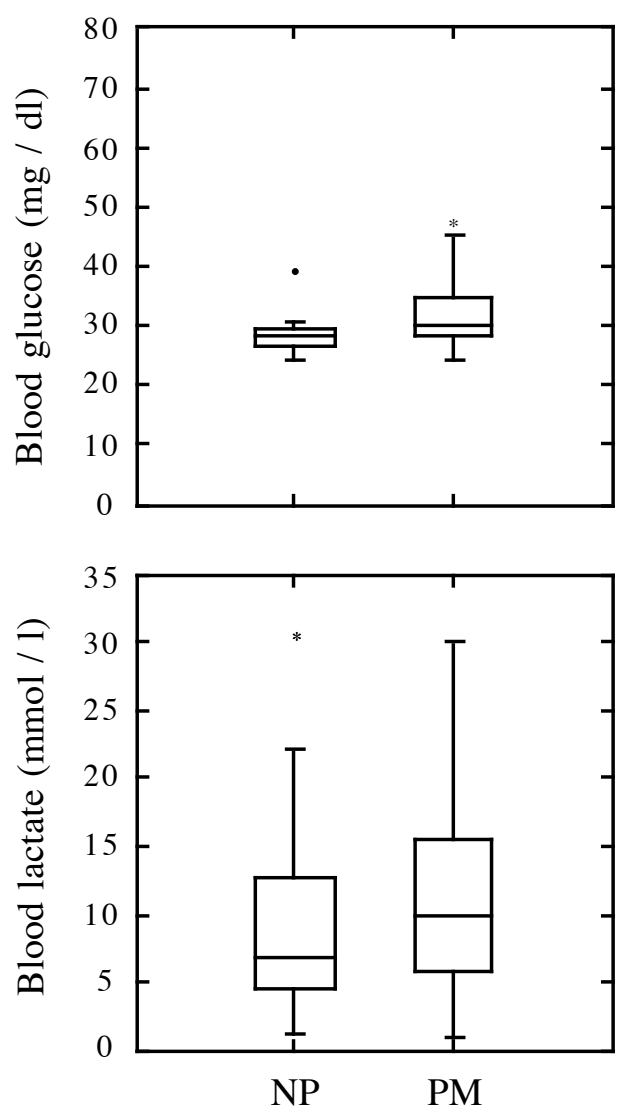

1-0 $\mathrm{h}$ before LT
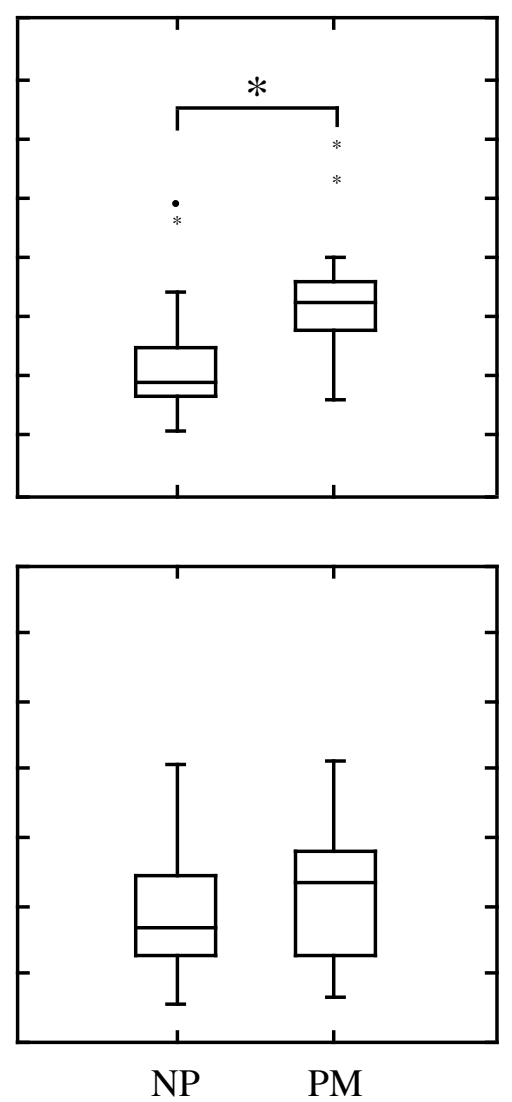

1-2 $\mathrm{h}$ after LT
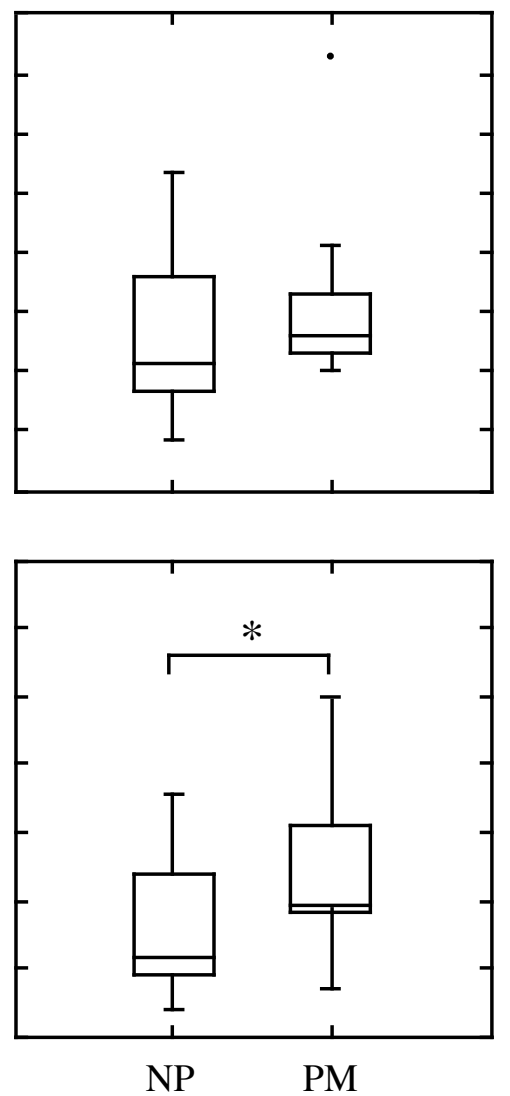
Figure 2. Blood-glucose and -lactate levels in P-males (PM) and NP-males (NP) at 'early' (2-1 h before LT; $N=15)$, 'middle' (1-0 h before LT; $N=15)$ and 'late' (1-2 h after LT; $N=15$ ) stages during their activity period. Since pillars are seldom built during the 'early' stage, haemolymph was sampled from P-males and NP-males that had and had not built, respectively, their pillars on the previous day. The median is marked by the center horizontal line. Lower and upper hinges comprise the edges of the central box. The hinges split the halves above and below the median into half again. Values outside the inner fences are plotted with the smaller asterisks. The inner fences are defined as follows: lower fence $=$ lower hinge $-(1.5 \mathrm{Hs})$, upper fence $=$ upper hinge + (1.5Hs). The outer fences: lower fence $=$ lower hinge $-(3 \mathrm{Hs})$, upper fence $=$ upper hinge $+(3 \mathrm{Hs}) . \mathrm{Hs}$ is the absolute value of the difference between the values of the two hinges (Wilkinson 1992). The individual number examined was shown below each box in the left figure. The larger asterisks indicate significant difference $\left(P<0.05, N_{l}=N_{2}=15\right)$. 
1-0 $\mathrm{h}$ before LT

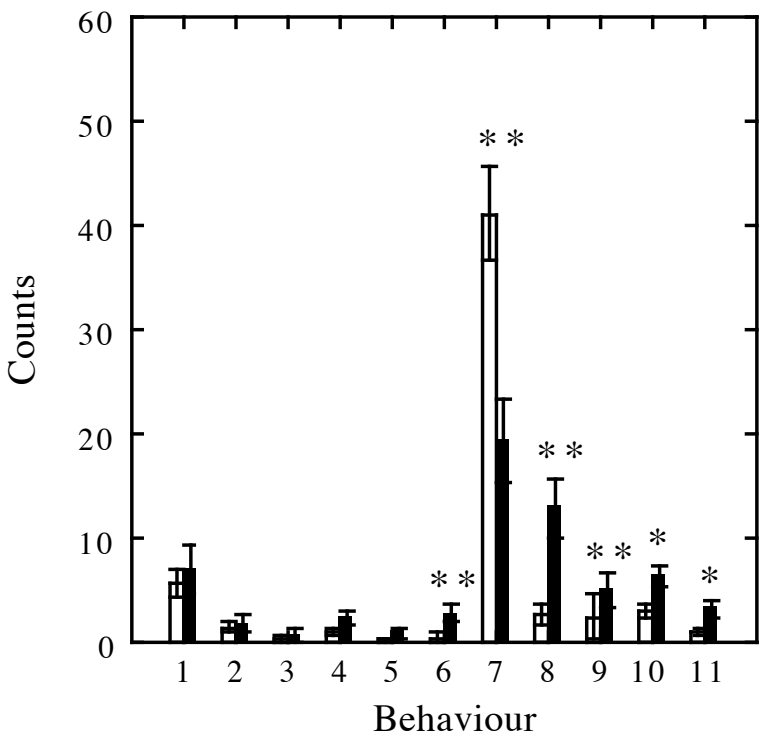

0-1 h after LT

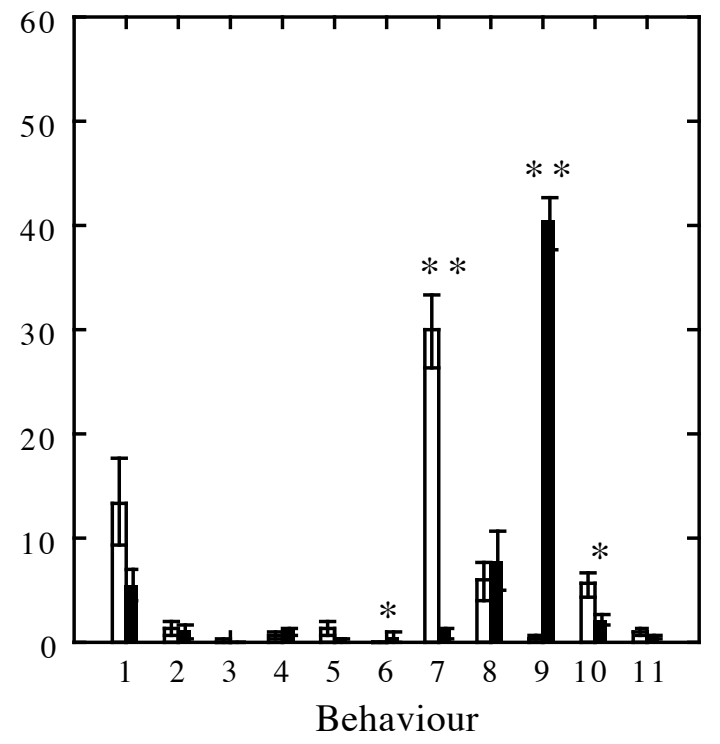


Figure 3. Behavioral differences between P-males (black bar) and NP-males (white bar) during 1-0 $\mathrm{h}$ before and 0-1 $\mathrm{h}$ after LT. Using the eleven behavioral categories defined by Christy (1988a) male behavior was recorded every minute for each of two 60-minute observation periods. Mean ( $\pm 1 \mathrm{SE})$ values are were shown $(N=14)$ : 1 "In burrow", 2 "Nothing", 3 "Pose", 4 “Clean", 5 "Dig", 6 "Pillar building”, 7 "Feed", 8 "Wave-feed", 9 "Wave", 10 "Threat", 11 "Combat" (see Table 1 for the behavioral categories). The asterisks indicate significant difference $\left(N_{l}=N_{2}=14\right):(*) P<0.05,(* *) P<0.01$. 